\title{
Essais
}

ESSAIS

Revue interdisciplinaire d'Humanités

$10 \mid 2016$

Faire-valoir et seconds couteaux

\section{Subverting Sidekicks - Representational Inversions and Instability in Kem Nunn's Tapping the Source}

Jeffrey Swartwood

\section{(2) OpenEdition}

Journals

\section{Electronic version}

URL: http://journals.openedition.org/essais/3878

DOI: 10.4000/essais.3878

ISSN: 2276-0970

Publisher

École doctorale Montaigne Humanités

\section{Printed version}

Date of publication: 15 September 2016

Number of pages: $81-96$

ISBN: 978-2-9544269-9-0

ISSN: 2417-4211

\section{Electronic reference}

Jeffrey Swartwood, «Subverting Sidekicks - Representational Inversions and Instability in Kem Nunn's Tapping the Source », Essais [Online], 10 | 2016, Online since 15 October 2020, connection on 26 October 2020. URL : http://journals.openedition.org/essais/3878; DOI : https://doi.org/10.4000/ essais.3878 


\title{
Subverting Sidekicks - Represen- tational Inversions and Instability in Kem Nunn's Tapping the Source
}

\author{
Jeffrey Swartwood
}

Like the physical world, the literary narrative can be seen as operating according to a system of rules and their transgression, explicit or implicit, governing among other things both transmission and reception. This article intends to focus on the mechanisms used by writer Kem Nunn in his 1984 novel Tapping the Source, and more specifically in those character constructions that can be categorized as sidekick figures with the goal of better understanding both the conception and transmission of the narrative. If, as our title suggests, the intent behind such constructions may be open to debate, their presence -indeed, almost omnipresence- in the text is a fertile ground for analysis.

In this paper, our analysis will be presented along two principal themes focusing on documenting and beginning to qualify the sidekick roles within Kem Nunn's narrative. The first section Establishing Sidekicks will examine the multi-faceted and sometimes contradictory secondary roles that the protagonist assumes. The plural from of sidekicks is used as Kem Nunn creates an interesting structure in which the main character serves as a sidekick -or underling- to two different heroes, or anti-heroes, in the course of this work. The second part of this text, Instability and Inversion, will then focus on how the sidekick construction is systematically deconstructed, inverted or abandoned in a series of developments that continually alter the narrative landscape and remove most any sense of constancy in the relationships between the characters in the narrative. While this paper places a great focus on documentation, it should be construed as a starting point for further analysis of the mechanics that Kem Nunn employs in a work that has largely influenced the Surf Noire genre.

Before plunging into the work itself, however, a brief introduction to both the author and his work within the genre recognized as Surf Noir will help to provide a constructive framework. Kem Nunn is a native Californian writer whose first work of fiction -Tapping the Source- was released in 1984. Subsequently, five other novels have been published, the most recent of which being Chance, published in English in 2014 and translated into French for 
a pending publication. The author has also developed a strong presence in American screenwriting, working on the HBO series Deadwood and Sons of Anarchy. For his fictional work, he has received a National Book Award (1984), Los Angeles Times Best Fiction Award (1984), Best Scenario from the Writers Guild of America for Deadwood (2007), and an Edgar Allen Poe Prize for best novel (1993), among others. This contextualization is intended to support the premise that despite its relatively little known status, this work and genre are to be seriously considered. This analysis thus seeks to contribute to the revision of the connotations of surf culture, a subculture that is simultaneously eulogized and yet decried as superficial despite its cultural impact and the growing body of serious work devoted to it.

While Kem Nunn's representational fictional writing is largely regional as a whole, certainly Western and more specifically Californian, this paper focuses on his contribution to the Surf Noir genre. Largely based in Southern California, intent on exploring the lesser-known or lesser developed aspects of the underside of surf culture, this genre draws both from the police or detective genres, notably from authors such as Raymond Chandler -and from the Western with its emphasis on the frontier and the maintenance or transgression of codes of conduct. ${ }^{1}$ In the case of Kem Nunn's work, there is also an element that appears to draw from the Southern Gothic tradition, with a highlighted sense of the exaggerated and the grotesque, ${ }^{2}$ though whether such elements are in fact exaggerated or grotesque is largely a question of perspective when relating a regional culture that is known for its extremes. ${ }^{3}$

Our examination is limited to Tapping the Source, a novel of particular interest in that it is one of the earliest works of this genre, and in many ways it appears to lay the groundwork for subsequent efforts. This novel also predates such literary ventures as Dean Kootz' Fear Nothing (1998), Thomas Pynchon's Inherent Vice (2009) and Don Winslow's The Dawn Patrol (2009), as well as a collection of short stories, Californios - a Surf Noir Collection published by Jeff McElroy in 2012.

1 These codes have been examined in great detail in both academic and popular press, frequently cited as consisting of individually tailored codes involving honor, independence, loyalty and bravery in an extra-institutional framework influenced by context. An effective synopsis can be found in Stephen McVeigh's The American Western (Edinburgh, Edinburgh University Press, 2007, p. 44-46).

2 Certainly it can be argued that Kem Nunn's writing matches Carson McCullers' description of "the tragic with the humorous, the immense with the trivial, the sacred with the bawdy, the whole soul of man with a materialistic detail." See: Carson McCuller, The Aesthetics of Place and the Comedy of Discomfort: Six Humorists (Ann Arbor, UMI, 2007, p. 96).

3 While the wide range of particulars are beyond the scope of this work, Southern California via its connotations with extremes ranging from Hollywood decadence to Hell's Angels violence, has a generalized reputation for larger-than-life proportions, both real and represented. 
Surf Noir writing provides a counter-representation of the Gidget-spawned mass culture vehicles, which dominated representations of surfing from the 1960 's through most of the 1980's, though it cannot be considered a complete rejection of the literary representations of the surfing sub-culture. Moments of description of the act of surfing itself are reminiscent of other works, including Jack London's writings on the subject, ${ }^{4}$ while the elevation of surfers, via the representation of larger-than-life figures, is reminiscent of those heroes of the quintessential American Western. ${ }^{5}$ In fact the surfer-outlaw connection extends back to at least the late $1940{ }^{\prime} s^{6}$ and is somewhat present, though in candied form, even in films such as Gidget. ${ }^{7}$ What Surf Noir does is to take the anti-hero figure, and the underside of surf culture, and move both to the forefront of the narrative, complexifying the beach landscapes potentially familiar to the audience.

To briefly synthesize the narrative, following the disappearance of his sister and a vague story from a fleeing surfer, a young man named Ike makes his way from an inland desert town to Huntington Beach in order to attempt to discover her fate. Once there, he slowly integrates the two dominant subcultures of this quintessential surf town on the verge of the massive changes brought about by the 1980s, which is to say the cultures of surfers and bikers. The town itself -dirty, gritty, and dark, alternating between alleyways, surf shops, flop hotels, and beer bars, is offered in its underground splendor, and in flagrant juxtaposition with the stereotypical visions of beach and of the ocean itself, though the latter is often also depicted as unwelcoming and violent as well: "angry, grey and black, streaked with white" (60). Becoming further involved with two main figures, a charismatic biker named Preston and a surfer-guru named Hound, Ike alternately explores these two social universes. Brought increasingly into a central role in each, he serves -at times simultaneously- as a sidekick to each of these men, as he pieces together the story of his sister's possible fate and tries to find his own place in the conflicting communities of Huntington Beach. Loyalties are tested, broken and mended, leading to a final choice between two representative figures in a conclusion that largely deconstructs relationships built throughout the novel. In short, most everyone either dies or flees the scene, in a mixed-message finale that we will return to in the conclusion.

4 Jack London originally wrote a detailed description of the act of surfing in his article "Riding the South Seas Surf" (Woman's Home Companion, 34:10, 1907) which was later incorporated into his novel Voyage of the Snark (New York, Macmillan, 1911).

5 See: McVeigh, p. 27-37, for an explanation of this elevation in popular American culture.

6 See the 2004 documentary film Riding Giants directed by Stacy Peralta or Nat Young's History of Surfing (Tucson, The Body Press, 1983, p. 53-67) for a brief introduction to this theme.

7 In the film Gidget, the figure of "Kahuna" played by Cliff Robertson is a Korean War veteran who initially resists reintegration into civilian society with its rules and regulations, preferring the decidedly anti-establishment of a "beach bum". 
But the primary focus of this text is on that of the representation and role of sidekick figure(s). The protagonist, Ike, serves as sidekick to two principal figures as the story develops, allowing the character to explore two different potential paths but also permitting those paths to connect. This construction provides what can be viewed as the intersecting links in the spiral DNA model of the narrative, the junctions between imperfect context and imperfect role models. How can we construe the forcible intersection of biker and surfer sub-cultures? In this particular setting, the combination is not altogether surprising: a Lords of Dog Town hybrid crossing with Easy Rider and perhaps a bit of Eastwood's Unforgiven is not an unreasonable representation of the Huntington Beach of the late 1970s. In such a mixed context, the choices that Ike makes are therefore choices based on shades of grey, rather than black and white, in an undermining of the traditional Western's clear-cut imagery that is much in line with the perpetual questioning of the revisionist Western narratives. ${ }^{8}$

\section{Establishing the side kick figure}

In certain texts, the sidekick role is made explicit, or is rendered obvious by association with one of the more famous existing sidekick relationships. But the adolescent-biker-surfer-sidekick model does not clearly follow these precedents, so we have to look for more subtle clues in the text.

Initially, when considering the narrative structure of the novel, it appeared that Ike clearly represented a sidekick to figures with greater experience and a higher level in the relative hierarchies of their sub-cultural groups. Upon closer examination, however, the clarity of that position wavered somewhat before again consolidating in an affirmative, though nuanced, position. This is partially due to an ongoing conversation with the author himself, who initially suggested that the relationships portrayed existed more along those lines of paternal role models, and partially due to the ongoing examination of the complex and contrasting roles played by each of the characters. At this point in the discussion, the author has acknowledged the sidekick element as being unconsciously but strongly present, while I have certainly deepened my appreciation for the complexity of his multi-faceted depictions. While lacking the clean bipolar structure of a Batman and Robin (dynamic) duo, or their interesting costumes for that matter, Ike nonetheless serves as a mostly

8 A visual concordance of this position is to be found in the frequent references to the "shades" or sunglasses worn by the characters, and put on and removed as if to provide a different filter through which to perceive the object of focus. At times, this transition is formalized as when "Morris methodically removed the wire-rimmed shades, folded them with great care, and slipped them into the pocked of his jacket" (141) prior to summarily knocking Ike to the ground. Seeing Ike both emotionally and physically hurt, and that with Preston's consent, marks a decided change of direction in the Ike-Preston relationship. 
loyal sidekick to Preston and a hesitantly loyal underling to Hound. One of the elements that can be insisted upon is that in this representation, as perhaps in life, there are consistently multiple perspectives and realities associated with relationships and actions. That Ike is searching for his sister does not exclude him from equally pursuing other aspects of his life. Similarly, that Ike is seeking a father figure does not keep him from adopting a sidekick role in his relationship with Hound Adams. The narrative figure can be simultaneously friend and sidekick, like Holmes and Watson, or mentor and sidekick, or even lover and sidekick, and the author explores each of these possibilities within his text.

In his relationship with Preston, the duo comes about unexpectedly, with Ike offhandedly proposing to adjust Preston's carburetor in a beach parking lot. Gaining acceptance for his knowledge of bikes, Ike then discovers that Preston is a 'former' surfer who helps him acquire a suitable board while 'getting back' at the shop where Ike had been ripped off, then helping with his surfing progression. Preston ultimately agrees to look into Ellen's disappearance, though he is not quite candid as to his knowledge of this event.

What he is though, throughout much of the text, is the dominant figure in their relationship. Does this alone, however, make Ike his sidekick? Examining the prevailing patterns, one can argue that yes it does. In the search for Ellen, it is Preston who determines the lines that the search will follow: directing Ike where and with whom to investigate, providing the insider perspective that allows Ike to decipher the complex social codes of the city, even providing pragmatic advice that allows Ike to progress in his surfing. In the realm of integrating the bikers, it is also Preston that provides the means for Ike to integrate the group, going so far as to "Put in a good word... as it were" (57) so that Ike can work with Morris.

Without being exhaustive, Preston provides Ike with a sense of direction and physical assistance, but their bond goes beyond this construct and the depth of their relationship is what makes Ike, in our sense, an interesting sidekick. While an excellent surfer, Preston had virtually given it up -he was "retired" to use Ike's terms- and yet he decides to bestow his comradeship and knowledge on Ike exclusively. His girlfriend confirms this when she states that "I mean, no one has been able to get Preston on a board in a long time..." (97-98). One simple gesture that Ike uses when going surfing with Preston, a touch on the arm to a man whose personal space is sacred, is highly revelatory of their relationship. "He touched Preston's arm as they started down. Thanks, he said, thanks for bringing me. Preston just laughed and led the way" (76). Preston has clearly not only brought Ike surfing and accepted Ike as his sidekick, he has brought him along in his life, in his quest, and he continues to lead the way though constantly encouraged or enabled by Ike. While not a "literate sidekick" in the sense of Williams and Zenger, he none- 
theless provides the intellectual stimulus "necessary to help the hero achieve his goals" -though in this instance the hero is not the protagonist and he is somewhat unclear as to the exact nature or extent of his own goals.

Further, Preston, normally evasive of extended conversation and compliments, is expansive with Ike on a multitude of subjects and even boasts to others of his skill as a mechanic. And, in a scene that we will develop further in the second part, he goes as far as to explicitly refer to Ike as his "partner" -a term that rings with sidekick associations across multiple genres.

Briefly, when Preston is injured, it is Ike who emotionally supports Preston's girlfriend. Ike is among the rare few who visit Preston in the hospital and during his convalescence, he offers assistance, and ultimately, Ike is the only non-biker present at Preston's funeral. Through these elements, we see the characteristics of loyalty and support that partially define a sidekick. While not always in agreement, Ike largely follows Preston's lead -despite the physical or emotional cost to himself.

A final episode is worthy of mention in establishing Ike as a sidekick, occurring near the conclusion, when Preston wants Ike to ride with him to check out the BSA. Instead of allowing Morris to assault Ike, Preston responds by elevating Ike's role in the partnership to potentially Biblical proportions ${ }^{10}$ : "Behold a pale horse", Preston croaked above the roar of the engine. "And his name that sat on him was death, and Hell followed with him"” (237). In a closed social context in which one's capacity for violence and destruction appears to concur with one's status -Ike is raised by this assertion into the inner circle- not on an equal footing with Preston, but riding close behind him. As the character of Morris more bluntly puts it, "Look, the little pussy's gone and grown himself some balls" (236). This quotation reinforces the elevated sexual status that Ike acquires, in a convergence of sidekick roles.

This scene, taken in conjunction with an earlier scene while Ike and Preston camp at the mythical Ranch 'secret spot', ${ }^{11}$ appears to support the idea of an

9 See: Bronwyn T. Williams and Zenger Amy A., Popular Culture and Representations of Literacy (New York, Rutledge, 2007, p. 100).

10 An analysis of the scriptural references in the novel is outside the scope of this work, but it should be noted that they are frequent and operative in the creation of tension between the elevated spiritual elements and the gritty underside of surf culture, a construct consistent with the Southern Gothic tradition of juxtaposition that warrants further exploration.

11 Nunn's ranch is based on the Hollister Ranch north of Santa Barbara, California -a surf spot rendered famous by Ron Stoner in the mid-1960s and frequently represented as a terrestrial surfing paradise. The ranch, off limit to surfers during its working period and currently difficult to access for non-residents, is part of the greater surfing mythology. See: Matt Warshaw, The Rise, Fall, and Mysterious Disappearance of Surfing's Greatest Photographer (San Francisco, Chronicle Books, 2006, p. 129-130) and Nat Young, History of Surfing (Tucson, The Body Press, 1983, p. 84-85). An interesting possible connection can be made to the Hearst Castle property, with its private movie theatre and relative isolation, in a blending of cultural references and popular mythologies. 
almost 'superheroesque' duo. ${ }^{12}$ "The last he saw of Preston, he was seated by the fire, a joint held to his lips, his dark hair loose, resting on his shoulders, so that he reminded Ike of certain airbrushed drawings he'd seen on the fuel tanks of bikes, the covers of magazines: the dark scowl beneath the long hair, the heavy tattooed shoulders and arms lit by the orange light of the fire. He looked like a figure out of some remote past, a slayer of dragons" (89). If Preston is indeed slaying dragons in this narrative then Ike is, ultimately as we will see in the conclusion, his faithful squire in a pairing that elevates the status of the quest and thereby its participants by this rich evocation.

The way in which Ike comes to serve as a sidekick to Hound Adams differs greatly from that of his relationship development with Preston, although as we will see there are certain parallels in their relationships. Ike deliberately seeks to join Hound's inner circle as a way to find out more about his sister. While some ambiguity remains as to Hound's real interest in adopting Ike into his circle, he nonetheless does so, helping him with surfing and finance, as well as providing an escapist development in terms of available sex and drugs.

Here again, one may ask if Ike is merely participating in Hound's activities, or if he is actually a sidekick to their instigator. Several clues indicate that the latter is actually occurring. A few of these include Hound's persistent use of the term hermanos del mar (114), ${ }^{13}$ indicating a higher level of comradeship. Associated with this is his overt offer to serve as a teacher or even a mentor to Ike when they meet at a party. Insinuating Ike's complex relationship with Preston, he states, "We all need a teacher, the trick is in finding the right one" (116). Hound thus appears in direct competition as that leading role. This relationship, both as it exists and as it might be further developed, is reinforced constantly throughout the second and third parts of the novel. When Ike has trouble surfing bigger waves, Hound offers "rest a minute, then we'll go out together. I'll show you the way" (161). The latter part of the sentence is clearly loaded in this moment of self-doubt for Ike.

And following this session, when a fight erupts between Bikers and Surfers, there is a key moment where Hound steps in to defend Ike, placing himself in danger to do so. This event not only exemplifies Hound's interest in Ike, it also provides the grounds for others to see them as linked. Michelle, Ike's girlfriend, sees this occasion as proof that Ike is indeed integrated into the inner circle at a special level. Other examples can be found in Hound's providing

12 Without pushing the comic book association, Ike's lower skill set as a surfer and status as a relative outsider to both surf and biker culture as practiced in Southern California, correspond to the Marvel Database definition: "The sidekick has the literary function of playing against the hero, often contrasting in skill, asking the questions the reader would ask, or performing functions not suited to the hero."

13 "Hermanos del mar" can be literally translated as "brothers of the sea" and is used alternately in Spanish and English (115) to make this perfectly clear. 
Ike with a board, of involving him in the drug traffic, of his continual offering of advice and counsel. Throughout the development of this relationship, it is interesting to note the parallels to Ike's dealings with Preston, the two leading figures appearing to be, in many ways, two sides of the same coin.

But again, does this make Ike Hound's sidekick or merely one of a close circle? Does Hound sharing advice and money and inclusion make Ike more than just one of several secondary figures? A key to seeing Ike as a sidekick appears near the final scene, when Ike is clearly distinguished from Hound's other associates, even those whose relationships are much older. In regards to Frank Bayer, Hound's shadow, he states that Ike is different. "We've worked well together, haven't we? And I could use someone new around the shop "I don't mean just working there, I mean really looking after things... I want to know things are in good hands when I'm gone... What about Frank?... Frank's a loser" Hound replies before saying to Ike "You could have it all" (259). Of course, in the context, Hound is not merely talking about the shop which is already the key to the social surfing universe; he is talking about the drug and pornography trade, about the travel and the lifestyle, even about access to the mythical Ranch surf spot - which in the narrative serves as a sort of Shangri-la incarnation of the ultimate goal. While Ike neither explicitly accepts nor refuses the offer, his de facto acceptance via participation appears to qualify him as a sidekick, though one with certain reservations.

One of the interesting elements in this novel is the way in which the figure of Ike appears to take a secondary role in his interaction with characters outside of the Preston/Hound binomial construction. Two examples will serve to illustrate this: Ike's relationship with Morris, a motorcycle mechanic who rides with Preston, and his relationship with Michelle -a runaway adolescent who is increasingly brought into Hound's inner circle.

The relationship with Morris begins uneasily as Ike offers to adjust the carburetor on Preston's Harley. A very drunk Preston agrees, over Morris's protests that he had already done the job. In the ensuing conversation and repair, several textual clues give one side of this representation. Preston asks rhetorically, "what's this... your little brother?" (34). While the question to Morris is rhetorical, it does draw an image of Ike as the little brother figure, or, in classic mainstream American iconography, the ultimate "sidekick" figure. That this sidekick can be a somewhat unwelcome accomplice is an element that we will develop further. After this initial introduction, Ike goes on to work at Morris's shop -and numerous descriptors are used "to help, to help out, to work with..." all in the close confines of the workshop. Thus Morris' status, both professional and within Preston's group, as a mechanic allows him to take the dominant role in a master-apprentice relationship in which Ike's ability to work is dependent upon his acceptance. While both Ike and Morris are unsure of this arrangement, it is Preston who ensures that the apprenticeship takes place and continues throughout the first half of the novel. It 
is tempting to see this structure as a hierarchy of sidekicks -Morris is clearly beneath Preston, although in his own clumsy way he is also a solidly reliable secondary figure, and the contention then lies in determining whether he or Ike have the dominant role. The fact that Preston regularly intervenes to keep Morris from physically harming his apprentice is one area in which the overlapping circles of relationships become clear. Still, on at least one face of what appears to be a many-sided coin, Ike is an underling figure to Morris as well.

The second relationship that is of interest is that of the primary love interest in the story -that is between Ike and Michelle. Coming from a very small town and being a self-described loaner, Ike admits to having no real experience with girls when he moves to Huntington Beach. Michelle, on the other hand, has had as the reader is to learn "lots of boyfriends" (118) and is much more worldwise. When their relationship begins, it is systematically Michelle who initiates the contact and interaction, and this dominant role extends into their sexual relationship in which she serves as the leader and mentor. She thus leads Ike -a hesitant though not exactly unwilling figure- into their experiences as a couple. In this process, Ike becomes what you might call a 'sexual sidekick' as both characters seek to develop a relationship and to experience something beyond the emotional doldrums of youth beach society.

\section{Instability and inversion}

Having carefully constructed a complex sidekick persona for his protagonist, the author also nearly systematically deconstructs those same relationships in his work. In what appears to be a reverse parallel structure, the interwoven interactions provide grounds for character development and complexification, with interesting results.

In part one of the novel (the novel is clearly divided into five parts), we saw how Preston slowly elevated Ike to sidekick status. In the second part, however, following a fight and his arrest, he distances himself in a surprising turn of events. Having already hidden certain aspects of his knowledge from Ike, the betrayal becomes increasingly manifest as the story continues. The most explicit rendering of this distancing takes place when Ike is walking down the street and suddenly finds himself confronted with Morris outside a bar. In a scene that could have initially taken place in a library, "Morris methodically removed the wire-rimmed shades, folded them with great care, and slipped them into the pocket of his jacket" before he "came after him, grinning broadly now, and swung" (141). The physical violence is secondary to the psychological impact of the episode. This is made evident when Preston appears, drunk and menacing, and Ike learns that he had allowed Morris to attack him on a bet that he could knock him out with a single punch. Any illusions of loyalty disappear as he says "Get the picture, queer bait?" (141) -adopting the homophobic language of Morris and thereby clearly excluding Ike. 
In the subsequent pages, Preston once again rejects not only Ike, but his association with surfing altogether, apparently regressing into the role of the simplistic biker. Even after he is hospitalized, when Ike comes to visit, his language is flagrantly aggressive and he repeatedly belittles and berates Ike with a series of slurs that ultimately reveal that he is aware of Ike's growing relationship with Hound. "You don't know shit. Working for Hound Adams. You think I don't know what's going down, what are you doing for him, pimping or letting him fuck you in the ass?" (217). Such altercations shift the focus of the text from the relationship between Ike and Preston to that between Ike and Hound -undermining much of what Ike thought he had developed in terms of community in the town. But the deconstruction is not unilateral: just as Preston is rejecting Ike, Ike himself had been, in a sense, betraying Preston by his increasing dealings with Hound. Both the leading and sidekick figures have thus been corrupted, with neither truly respecting their roles.

It is not until the conclusion that this relationship is again inverted, with Preston's apology for the physical attack on Ike with the simple statement explanation: "I was wrong to let that happen. You were my partner, man. And I never stood back and let a partner get dumped on that like that before. I was kind of hoping it would scare your skinny ass out of town. But I was wrong to let it happen" (239). Here we see the repletion of the term partner, and the emphasis upon the elevated status that Ike had, through the use of the past tense in regards to that status also indicates that their relationship has devolved. Paradoxically, in the assertion of the sidekick relationship that existed, and that its demise was in fact a form of loyalty, is also found the confirmation that it has been broken. This construction appears to both elevate and undermine the relationship, as being faithful to one's sidekick may in fact mean losing him.

Another form of inversion takes place in the subtext of primary narrative. While Ike is explicitly the second-figure in this duo, it is interesting to note that it is in fact Ike who often takes the dominant role. If Preston's involvement in surfing is one that he highly values, one that represents a potential return to the "hero" status and relative innocence that he had in his youth, it is only through Ike that this renewal becomes possible. Further, while Preston is presented as almost the "ultimate" biker -from his tattoos to his heavy boots and his physical domination of his surroundings- it is Ike that allows him to do so: first, through the repair of his motorcycle, and second, through the conception of a suicideshift system that allows Preston to ride even after his hands are injured. It is Ike's insistence, rather than Preston's, that finally allows Preston to confront his past and his own passivity concerning Hound's actions. In his albeit flawed consistency, Ike proves to be the driving force in the relationship in many ways. The instability inherent in this process greatly contributes to the tension in the novel and the general ambience of uncertainty. 
As Ike's relationship with Preston changes, so does that with Hound: he apparently forsakes one mentor for another. This switch is fundamentally driven by Ike's quest to find his sister but is also a function of his developing integration into the darker local culture of underage sex and drugs. But just as his relationship with Preston proves to be unstable, Ike's role as a sidekick to Hound is constantly undermined.

While Ike gains access to Hound's inner circle, it is an access that is based on dishonesty from Ike as he is already suspicious of a potential role in his sister's disappearance. As the narrative progresses, the reader becomes aware that Hound was aware of this deception and goes along with it, as "a good game makes life more interesting” (258). He is, himself, constantly misleading or deceiving Ike as to his real intentions and knowledge, at one point provoking Ike to reflect that a comment made about Preston "was the first honest thing that Hound had told him" (224).

This point leads us to another level of undermining of the sidekick role: it is consistent neither in its duplicity nor in its honesty. The character of Hound alternately offers Ike inclusion and exclusion in response to a rapidly changing scenario, while Ike honestly debates with himself about simply adopting the sidekick role -with its many fringe benefits- and allowing his reservations and relationships with Preston or Michelle to disappear. In the end, both Ike and Hound reject their relationship though in different ways and for different reasons: Ike doing so when he chooses Michelle over Hound's proposal to take their relationship, or their "voyage of discovery" (258) as he puts it, to the next level, and Hound doing so when he agrees to sacrifice Ike for a pornographic "snuff film" in order to maintain his position with his benefactor. This betrayal is a partial parallel to that of Preston, but with infinitely more dramatic consequences.

Essentially, despite the high valorization of surfing in the novel, the "hermanos del mar" rhetoric is shown as an empty promise -a relationship of convenience that may provide a temporary sense of conviction but which signifies nothing when sacrifice is required. As discussed earlier, the sidekick characteristics assigned to Ike extend to his relationships with the secondary figures in the narrative. And just as the author is extremely consistent in his portrayal of Ike's role in these relationships with the main characters, Kem Nunn also extends his inversions and undermining of the sidekick role -whether willing or unwilling- to those interactions with the secondary figures.

In the relationship with Morris, it is Morris who is the recognized mechanic among the bikers in Preston's group. However, it is Ike who holds the real skill and in fact far surpasses Morris in his ability as a mechanic. In the scene of their initial meeting, it is Ike who knows how to adjust the carburetor whereas Morris has failed. Ike then repairs Preston's gas tank, and while using Morris' tools and space, accomplishes a better job than Morris could 
have hoped to have done. He also handles Harley renovations with which, implicitly, it is understood that Morris would have had problems undertaking on his own. Thus the realities of the roles are inverted: while technically the mentor, it is Ike who has the real skills and role of mechanic. Even towards the end of the novel, when Morris modifies a bike so that an injured Preston can ride, he does so using plans drawn up by Ike. This underlying tension, not only in the explicit dislike that Ike and Morris harbor for one another -a conflict frequently bordering on and occasionally spilling into physical violence- but also in the form of constantly changing relational dynamics, serves as an additional source of constant unease for the reader. Nowhere, it seems, are the structures clearly defined and concrete. Instead, the main character, like the reader, is left to negotiate fluctuations in context like one negotiates the changing surges of an ocean than one can accommodate but certainly not master.

The other important relationship that we have discussed is that between Ike and Michelle, one in which Michelle initially provides the leading role. As Ike is drawn into Hound's inner circle, and increasingly exposed to the drug-related and sexual aspects -including adolescent pornography- he, in turn, becomes the more experienced and controlling of the two. This is made clear not only through the profusion of partners, scenarios, and experiences that Ike accumulates in a brief time, but also in his desire to impose certain aspects of this new experience in his relationship with Michelle. In this turn of events, it is she who is led -and not always willingly- into the next stages of their couple prior to its demise. Again, the relationship which appeared to provide Ike with his most sure refuge in the earlier stages of the novel, is deconstructed: the roles inverted and the loyalties broken, removing the primary source of surety for the protagonist and reader alike.

The inversion of the roles takes place only gradually, and the reader is never sure at what point it will stop -or to what extent this inversion is interrelated with other inversions in the narrative. Without going into a lengthy plot description, there are multiple conflicts between Ike's relationship with Michelle and that he has with Hound. Supporting Hound may mean betraying Michelle, and vice-versa, rendering Ike a dubious sidekick at times. The extent to which this duality is present is expressed explicitly in the conclusion to the second part on the novel when Ike, having cheated on Michelle expresses his own conflicts as "some vicious circle in his head" as he explores his possibilities: "Somewhere in the midst of all that guilt and disgust, there was this other feeling that was in some way connected to that curiosity about himself he had felt earlier, a dark sense of satisfaction lurking in the gritty morning, a sense of awe almost, at what he had done, him, Low Boy..." (186). Brusquely, the reader is reminded that despite his secondary-figure status in relation to other characters (here confirmed by the capitalized title 
"Low Boy" that he gives himself), Ike is indeed at the center of his own narrative and is himself having to negotiate his way through his multiple quests, including that for his own identity. This complexity is certainly operative in the narrative, providing not only a sense of realism but also uncertainty as the perspective provided through Ike is in constant flux and therefore potentially unreliable at any given moment.

This element of ambiguity is drawn out, and coupled with the sexual tension present in the text, sometimes takes on subtle forms. For instance, towards the end of the novel when Ike is seeking reconciliation, he surfs just before joining Michelle on the beach. Her comment, "You're getting good, I was watching" (246) precedes their making love. However, in light of the sexuality of the scene, there is a lingering doubt: was she referring to his progress in surfing (itself an inversion of his previously dismal status as a surfer) or was she making a reference to the pornographic movies in which he played an increasingly active role and which she has perhaps seen? In the latter case, she is affirming the reversal of his earlier sexual inexperience and awkwardness as well as introducing the notion that Ike himself was an accessory -or sidekick- in the film making process both. While it is certain that his underling role is being contested, or inverted, whether this inversion corresponds to Hound or to Michelle is unclear.

While this relationship is eventually "righted", though in a manner that is forced to accept the multiple inversions and failings, it does so with a note of hopeful uncertainty. This aspect of the work, the recognition of a flawed existence and yet a persistent sense of hope, is one that we will return to in the conclusion.

\section{Conclusions}

The profusion of sidekick representations in Tapping the Source virtually forces the reader to constantly realign their perception figures and relationships within the narrative. Within this process of realignment, the frequent inversions of leading and secondary figures create an apparently unusual situation: while becoming increasingly aware of the literary sidekick construct the reader is potentially also increasingly led to question its role, and even perhaps its relevance. While Kem Nunn has apparently gone to great lengths in the construction of secondary figures or sidekick roles in Tapping the Source, it also appears that he has gone to nearly as great of lengths in their deconstruction. Heroic figures are successively elevated to the lead status as the protagonist attempts to negotiate his own quest, only to be successively reduced in Ike's esteem before a final scene of confrontation and redemption, at least in the case of Preston. Confrontation and contradiction thus seem as much a part of the relational landscape as do the traits of consistency and loyalty, sub currents boiling unexpectedly to the surface. 
While a sidekick to both Preston and Hound in most senses, it is Ike that leads Preston to rediscover himself, and perhaps a better path, rather than the other way around, and it is Ike who ultimately works the social machine that Hound Adams so carefully observes, in order to meet his own objectives, and again, it is Ike who, ultimately, physically survives.

In the conclusion, the author is playing on a theme that is common to both the Western and the Surf Noir genres, that of a dramatic confrontation involving some form of self-sacrifice. From James Stewart's last stand in Fort Apache, to Clint Eastwood's final showdown in Unforgiven, passing by the over-the-top dark comic mayhem of Fred Reiss's finale in his 1995 Gidget Must Die, the final confrontation is one of the longstanding hallmarks of frontier literature -whether that frontier lies in the desert or near the Pacific. In this case, Preston confronts his own role in Hound's criminal activities, and puts an end to them while sacrificing himself in order to do so. It is this conclusion, however, that allows Ike both to reclaim and to surpass his sidekick roll: by reestablishing Preston as the leading figure that Ike had hoped him to be, and yet in his removal (literally by his death) Ike is able to truly free himself to move on -leaving both this particular physical setting and the turmoil of conflicted loyalties that are inherent to it. This final confrontation also allows Ike, in a turn reminiscent of John Wayne's romantic involvement in Stagecoach, to begin anew with Michelle after their respective failings.

In crafting his novel Kem Nunn appears to be, deliberately or unconsciously, subverting the sidekick role or at the very least providing the reader with another perspective on it. Through intersecting storylines, inverted hierarchies, utilization and ultimate rejection of categorical sidekicks, the author leads the reader further into the realm of uncertainty. If Ike ceases to be Preston's sidekick, whether in the water or in a greater sphere in the selection of both characters' life paths, can we question whether he has ever really been a sidekick at all? Here, the author's emphasis on conveying $a$ reality -though perhaps not an exclusive reality- not only in terms of a specific place and time but of a broader human experience -comes into play.

While clearly a sidekick, often playing a secondary part in his own narrative, Ike is never reduced to "a companion who sometimes gives the protagonist important information or insights" ${ }^{\text {" }}$. Instead, while serving as the foil to other characters in certain strands of the story, Ike remains above all his own central figure, ultimately responsible for his own decisions and courses of action. Escaping a certain form of cliché in an effort at depicting complex social realities, the author reminds us that relationships are neither simple nor static, and that the individual is always part of a larger whole -one which

14 Turco, Lewis, The Book of Literary Terms (Hanover, University Press of New England, 1999, p. 49). 
can, though not always easily -provide a context for personal and collective growth. This analysis appears to concur with the author's position, explained in a June 2104 interview:

Another way to think about this maybe in the context of community. If it's true, and I think it is, that we find the highest expression of our humanity in community, well then that's a kind of fluid thing. One might need to be a leader one day, a follower the next. I often write about characters who begin in some form of isolation, then something happens, some inciting incident, and they are pitched into the world and forced to make some accounting for themselves with regard to others and I think that this is true of Ike. ${ }^{15}$

Of course, all fiction and all sidekick relationships depict some form of reality. Fans of Batman and Robin can assuredly find valid social and philosophical statements and criticism being forwarded in the complex causalities in the nefarious deeds of the cast of Gotham City's underworld as well as the caped crusader's attempts to foil them. But here, Kem Nunn escapes the binary construct common to most sidekick relationships, broadening the scope of possibilities in his narrative -both a step closer to realism and a crucial element in setting the tone of his work.

This emphasis on reciprocity within the community also provides a humanistic counterpoint to the grit and violence that is contextually present in the narrative. Undermining the sidekick role runs parallel to undermining, in a sense, the noir in surf noir: for the narrative can be viewed as a success story. Preston's ultimate redemption and Ike's sense of belonging allow a tentatively optimistic ending, despite the erring and sense of loss.

While he may not be riding into the sunset on a white stallion (even the esteemed '36 Harley Davidson Knucklehead is forsaken in the end, replaced by a more efficient BSA) Ike's departure in a Greyhound bus is nonetheless a sort of victory. Elevated by association with the classical Western image of the heroic departure as well as with disassociation with a potentially redeemed Preston via the representation of the means of transport, Ike remains true to his hybrid narrative nature. Riding off to an uncertain future in rainy Oregon, Ike as a leading figure-sidekick composite is nonetheless offered the chance at a new beginning while aware of, and at times even savoring, life's inescapable flaws.

Jeffrey Swartwood

EA 4196 CLIMAS

École Polytechnique jswartwood@aliceadsl.fr

15 This interview was conducted over a period of several weeks, during June and July of 2014. 


\begin{abstract}
This paper focuses on documenting and beginning to qualify the sidekick roles within Kem Nunn's Surf Noire narrative, Tapping the Source. Our goal is to examine the multifaceted and sometimes contradictory secondary roles created by the author as a starting point for further analysis of the mechanics that Kem Nunn employs in a work that has largely influenced the emerging Surf Noire genre.
\end{abstract}

\title{
Keywords
}

Sidekicks, Kem Nunn, surf culture, noir fiction.

\section{Résumé}

L'objectif de ce texte est la documentation - ainsi que le début d'une analyse critique - des rôles de second couteau dans le récit Tapping the Source de l'écrivain Kem Nunn. Cette exploration des rôles complexes et parfois contradictoires des personnages créés par l'auteur est un point de départ pour une analyse plus profonde de la mécanique narrative employée dans un livre qui a largement contribué à l'émergence du genre Surf Noire.

\section{Mots-clés}

Faire-valoir, Kem Nunn, surf, roman noir. 